\title{
TU/e EmonONEN

\section{An experimental approach to evaluate the dynamic behavior of the human knee}

\section{Citation for published version (APA):}

Dortmans, L. J. M. G., Jans, H. W. J., Sauren, A. A. H. J., \& Huson, A. (1988). An experimental approach to evaluate the dynamic behavior of the human knee. Journal of Biomechanical Engineering: Transactions of the ASME, 110(1), 69-73.

\section{Document status and date:}

Published: 01/01/1988

\section{Document Version:}

Publisher's PDF, also known as Version of Record (includes final page, issue and volume numbers)

\section{Please check the document version of this publication:}

- A submitted manuscript is the version of the article upon submission and before peer-review. There can be important differences between the submitted version and the official published version of record. People interested in the research are advised to contact the author for the final version of the publication, or visit the $\mathrm{DOI}$ to the publisher's website.

- The final author version and the galley proof are versions of the publication after peer review.

- The final published version features the final layout of the paper including the volume, issue and page numbers.

Link to publication

\section{General rights}

Copyright and moral rights for the publications made accessible in the public portal are retained by the authors and/or other copyright owners and it is a condition of accessing publications that users recognise and abide by the legal requirements associated with these rights.

- Users may download and print one copy of any publication from the public portal for the purpose of private study or research.

- You may not further distribute the material or use it for any profit-making activity or commercial gain

- You may freely distribute the URL identifying the publication in the public portal.

If the publication is distributed under the terms of Article 25fa of the Dutch Copyright Act, indicated by the "Taverne" license above, please follow below link for the End User Agreement:

www.tue.nl/taverne

Take down policy

If you believe that this document breaches copyright please contact us at:

openaccess@tue.nl

providing details and we will investigate your claim. 


\section{H.w. J. Jans Evaluate the Dynamic Behavior of the Human Knee

\section{Introduction}

Dynamic loading of the human knee joint is a frequently ocurring event in many human activities. For example, during walking pulse-like loads are exerted on the foot resulting in shock waves of accelerations (deformations) that are transmitted through the tarsal bones, the lower and upper ankle joint, and the tibia before reaching the knee joint [1], [2]. It has been observed that the knee joint plays an important role in this transmission of dynamic loads by acting as a kind of shock absorber, thus reducing the amplitudes of the loads to be transmitted. Voloshin and Wosk [3] studied this phenomenon by defining an attenuation factor which is the quotient of the maximum amplitudes of the accelerations measured on the tibia and the femur during walking. They showed this attenuaculd reach values of 1.5 . This attenuation factor tion factor could reach values of the behavior of the knee joint; gives only a global indication is obtained about the frequency for example, no information is obtained about the signals. contents of and phase shift betweed that the human knee is a

In this context it must be realized that highly incongruent very complicated joint. First, due to its highly inconge menisci, load bearing areas, additional elements an important role ligaments, capsule, and muscles must play an insocondly, they in the maintenance of its required of dynamic loads. Apart may also influence the transmission of dynamic shock from the fact that muscles themselves mat muscular activity sorbers, Markolf [4] has demonstrated that mnee joint.

can result in considerable stiffening of the kneen loads exerted

Furthermore, nonlinear relationships between reasons for this and loads transmitted may be expected. The real investigations, are that, both in experimental and theor behavior under static the knee joint shows a strongly nonlinear behavious parts of the loads [5-8]. It has also been observed that varime-dependent material joint have (strongly) nonlinear, time-dependent material

the JoURNAL of Contributed by the Bioengineering Division for pub bioengineering DiviBIOMECHANICAI. ENGNEERING. Manuscript received by the Bloenger properties ([9], [10]). Therefore, the use of linear-systems theories (e.g. rigid mass-linear spring-linear dashpot models) 11] or models in which the elasticity of joint elements such as menisci and cartilage layers is not taken into account [12], is ikely to be inadequate to describe the dynamic behavior of the human knee joint under physiological loading.

In this paper a method and the resulting experimental equipanted for in vitro investigations of the behavior the human knee joint under controlled dynamic loading. To illustrate the form in which data become available and to indicate the kinds of phenomena observed, some results obtained from a series of preliminary experiments for one knee joint specimen are given.

This work constitutes the first stage of a long-term research project that was started to obtain more insight into the behavior of the human knee joint and to assess the possible importance of the factors discussed above. The ultimate goal of the project is the development of an experimentally validated theoretical model which has parameters that can be interpreted in terms of the properties and functions of joint elements and the interactions between elements.

esulting model may provide new starting points for the ptimization of diagnostic methods and tools (the identification of critical parts of dynamically loaded ligaments and capwell as for the evaluation of treatments of the joint for disease and trauma (e.g., the consequences of meniscectomy or the los and repair of ligaments). Moreover, the model is expected to be a useful tool for investigations of the influence of knee endoprostheses on the dynamic behavior of the joint.

2.1 Material and Methods. Due to the complexity menioned in the introduction and the fact that, to our knowledge, little fundamental research has been done on the transmission f dynamic loads through the knee joint, it seemed sensible to start with an exploratory experimental investigation of the start with an exploratory experimental in knee joint under 


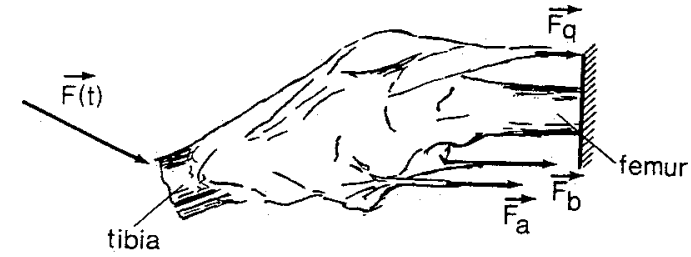

Fig. 1 Schematic view of a joint specimen clamped at the femur and loaded with a dynamic force $F(t)$ at the tibia while static tensile forces $\underline{F}_{a}, \underline{F}_{b}$ and $\underline{F}_{q}$ are acting at the tendinous muscle attachments

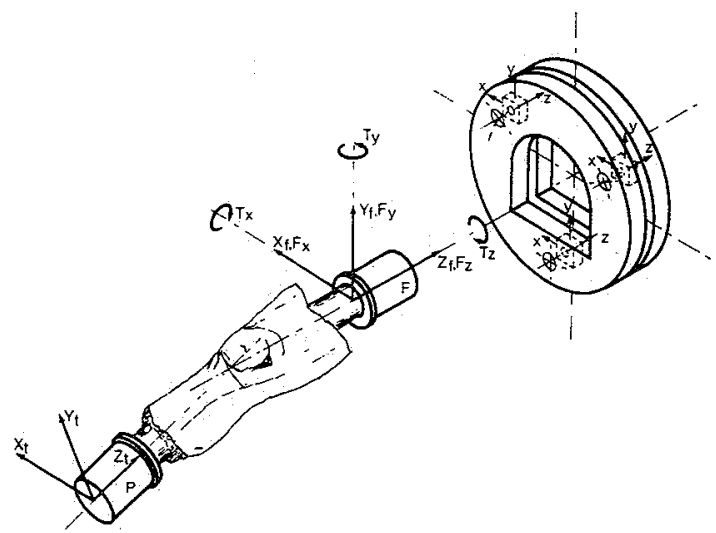

Fig. 2 Definition of coordinate systems, reaction forces and torques

dynamic loading. For ethical and technical reasons these experiments will be done on human knee joint specimens in vitro. In vitro experiments also allow for the development of suitable experimental procedures to measure relevant quantities inside and outside the knee joint under controlled dynamic loading.

This paper describes the experimental study of one knee specimen. The human knee joint specimen used consisted of the distal part of the femur and the proximal part of the tibia, each approximately $20 \mathrm{~cm}$ long, with a limited number of tendinous muscle attachments preserved but with muscular tissue entirely removed. Joint elements such as the capsule, ligaments, articular cartilage layers, menisci, and patella were preserved. The specimen was rigidly clamped at the femur (Fig. 1).

Static forces $E_{q}, E_{b}$ and $E_{a}$ were exerted on the tendons of the following muscles: rectus femoris, biceps femoris, and sartorius. These static loads were not meant to simulate muscular activity, but were merely a technical solution for both creating a stable, global equilibrium position of the tibia in space and for exerting a (compressive) static preload on the knee joint that could influence its dynamic behavior. In this way an equilibrium position was created with as few as possible (3) forces without imposing kinematic constraints other than those originating from interaction of the articular surfaces and ligamentous structures.

The static equilibrium position can be described by means of two Cartesian coordinate systems (Fig. 2). Coordinate system $\left(X_{f}, Y_{f}, Z_{f}\right)$ is rigidly attached to the femur with its origin on the longitudinal axis of cylinder $(F)$ and in the center of the top plane of this cylinder, such that the $Z_{f}$-axis coincides with the longitudinal axis of the cylinder and is approximately parallel to the longitudinal axis of the shaft of the femur. The positive $Y_{f}$ direction is opposite to gravity such that the $Y_{f}-Z_{f}$ plane approximately coincides with the sagittal plane of the femur. The coordinate system $\left(X_{t}, Y_{t}, Z_{t}\right)$ is rigidly attached to the tibia with its origin on the longitudinal axis of cylinder $(P)$ and in the center of the bottom plane of this cylinder, such that the $Z_{t}$-axis coincides with the longitudinal axis of this cylinder and is approximately parallel

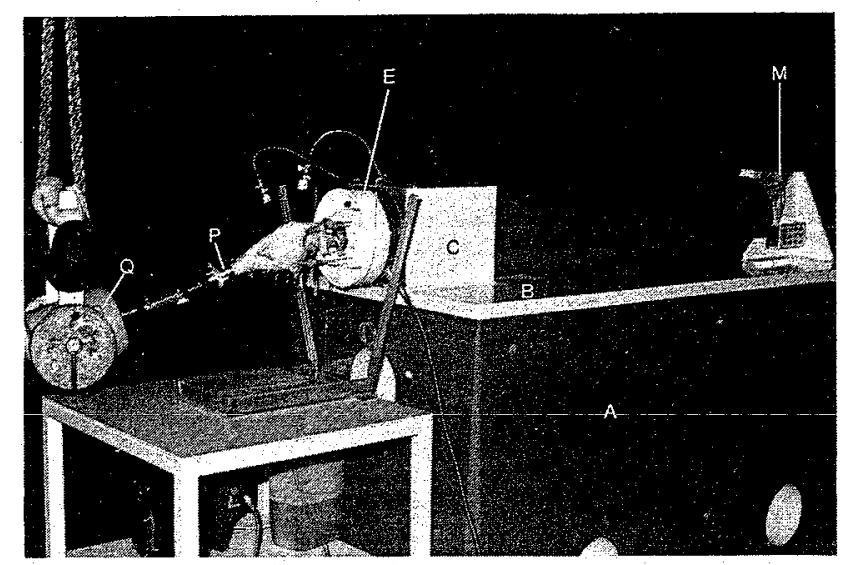

Fig. 3 Overview of the experimental setup

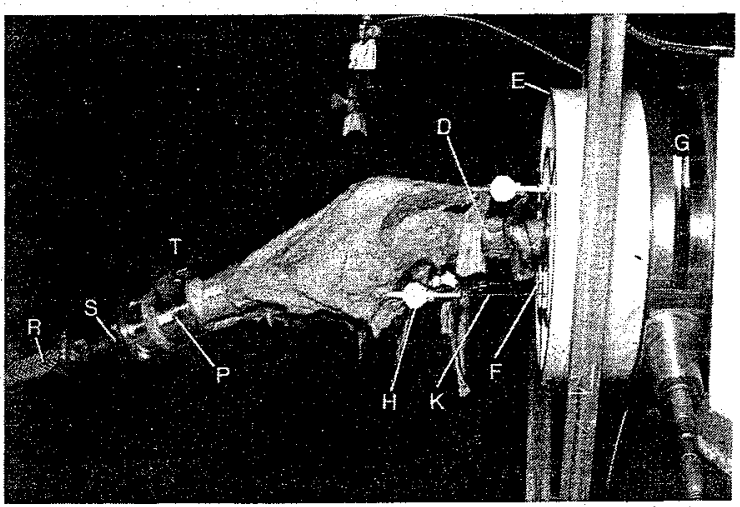

Fig. 4 Knee joint specimen mounted in the experimental setup

to the longitudinal axis of the shaft of the tibia. In full extension the $Y_{t}$ and $Y_{f}$ axes are chosen to be parallel.

Relatively small dynamic loads were exerted on the distal part of the tibia such that only small displacements of the tibia relative to the femur occurred. To obtain information on the frequency content of these loads, the accelerations measured by Voloshin ([1], [3]) were analyzed by means of Fast Fourier Transformation (FFT) resulting in the indication that the frequency interval of interest ranges from 0 to $100 \mathrm{~Hz}$. This range is larger than the range of $0.5-10 \mathrm{~Hz}$ covered in the impedance measurements of Crowninshield et al. [11] but is consistent with the results obtained by Antonsson [2], concerning the frequency content of the ground reaction forces on the foot during walking. With the assumption that the knee joint behaves as an instantaneous linear system under the conditions mentioned (small dynamic loads, small displacements), it was decided to use bandwidth-limited random white noise in the range 0 to $100 \mathrm{~Hz}$ for the small dynamic loads applied to the tibia.

Correlations between the responses of the joint (e.g., accelerations of the tibia and reaction forces and torques at the clamped side of the femur) and the applied loads were formulated in terms of transfer functions [13]. These transfer functions provided a means to validate the assumption of linearity.

2.2 Description of the Experimental Setup. An overview of our experimental setup is given in Fig. 3. A rectangular concrete block (A) (width $\times$ length $\times$ height $=0.8 \times 1.6 \times 1.0 \mathrm{~m}$ ) with a steel plate (B) rigidly attached to its upper plane constitutes the basis of the setup. A rectangular steel block (C) $(25 \times 25 \times 30 \mathrm{~cm})$ is welded to one of the short sides of the steel plate and a grate (M) with eight vertical slots is welded to the other. A clamping flange $(E)$ is mounted on a threedimensional platform $(G)$ and this unit is attached to block $(C)$ 


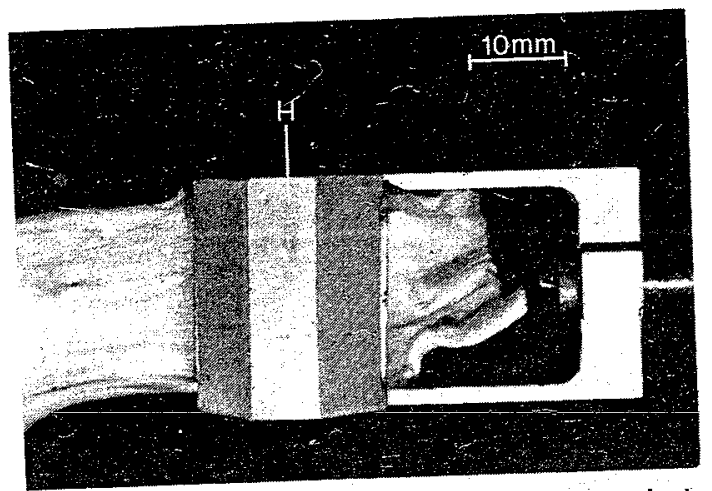

Fig. 5 Top-view of a clamp connecting a bracing wire and a tendon

(see Figs. 3 and 4). The three-dimensional force-platform was developed in cooperation with Kistler $A G$, and consists of three, three-dimensional piezo-electric load cells (Kistler 9251) mounted, under a preload of $9 \mathrm{kN}$, between two circular plates. Experimental analyses have shown the dynamic stiffness of this portion of the apparatus to be higher than $10^{9}$ $\mathrm{N} / \mathrm{m}$ within the frequency range of $0-100 \mathrm{~Hz}$.

The proximal part of the femur (D) is fixed in a stainless steel cylinder $(F)$ with the use of a rapidly curing polymer (Fastacryl). The cylinder is subsequently mounted into the clamping flange (E). Static forces on the tendons, described in the previous section, are generated with the use of three bracing wires (K) (length $1.5 \mathrm{~m}$, diameter $1 \mathrm{~mm}$ ) which are attached to the tendons by means of self-tightening, slip-free clamps (H) (Figs. 4 and 5). Each clamp weighs $26 \mathrm{~g}$ and is capable of transmitting forces up to $1500 \mathrm{~N}$. The wires pass through holes in the flange (E), force-platform (G), and block (C), and are connected to a stud-and-nut combination (N), placed in one of the slots of grate (M) (Fig. 6). A desired tenile force in the wire is generated by turning the nut and can be measured with strain gages glued to the stud. The dimensions of the wires were chosen to attain a stiffness as low as $10^{5} \mathrm{~N} / \mathrm{m}$ and a loading capacity of $2000 \mathrm{~N}$. Because of this low stiffness, possible force fluctuations in the wires resulting from small length variations during dynamic excitation of the tibia, are kept as small as possible.

The distal part of the tibia is fixed into a stainless steel cylinder (P) to which an electro-mechanical shaker (Q) (Ling Dynamics; model 403) can be attached in an arbitrary direction by means of a flexible hose (R). This hose prevents the knee joint from being kinematically constrained by the shaker and eliminates undesired force inputs induced by lowfrequency, environmental vibrations. Applied forces can be measured by a piezo-electric force transducer (S) (Kistler 9301A) which is mounted between the hose and the cylinder (P) and vibrations of the tibia can be measured with an accelerometer ( $T$ ) (Brüel and Kjaer 4367) attached to the cylinder $(\mathrm{P})$. The lowest resonance frequency of the test apparatus is $124 \mathrm{~Hz}$ which is sufficiently greater than the resonance frequencies of the joint specimens (see Section 3 ).

2.3 Measurement-Control and Processing System. A measurement-control and processing system was developed that consists of an IBM PC/XT personal computer equipped with a laboratory interface (TECMAR Labmaster). To supply the dynamic input force acting on the tibia, this system generates a random signal with adjustable frequency content. Furthermore, it enables the measurement of up to 16 analog signals and the storage of the sampled data. Before being digitized, all measured analog signals are properly filtered (low-pass; $48 \mathrm{~dB}$ /octave) by means of a 16 channel filter-unit specially developed for this purpose. Data acquisition is done under software control at a rate of at most $600 \mathrm{~Hz}$ for all 16 channels. To ensure simultaneous measurement of all 16 chan-

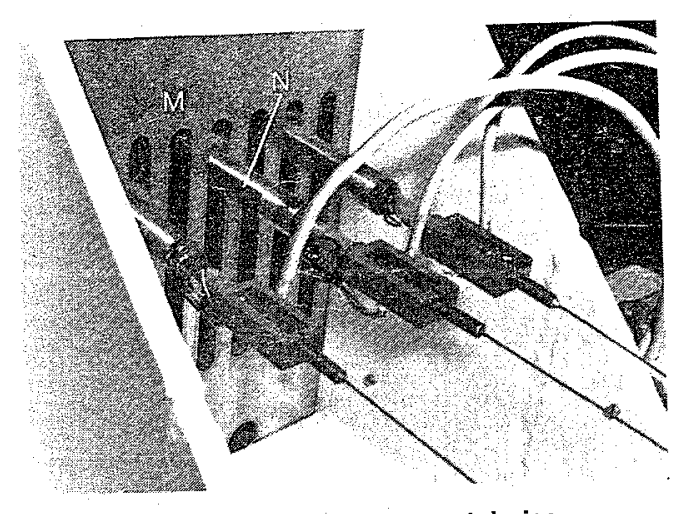

Fig. 6 Preload adjustment device

nels, use is made of 16 sample-hold circuits and a multiplexer. Analog signals to control these sample-hold circuits and the cutoff frequency of the analog filters are generated under software control. To produce the desired transfer functions, software has been developed based on Fast Fourier Transform techniques and Transfer Function Analysis (TFA) [13].

Using this data acquisition system the dynamic input force $F(t)$, accelerations on the tibia, reaction forces $F_{x}, F_{y}, F_{z}$ and reaction torques $T_{x}, T_{y}, T_{z}$ were measured with a sampling rate of $300 \mathrm{~Hz}$ during 68 seconds. Using a 1024-point FFT the digital signals were subsequently used in an unweighted averaging process to obtain power spectra and transfer functions between two arbitrary signals in 512 points in the frequency domain in the range from 0 to $150 \mathrm{~Hz}$. However, due to the use of piezo-electric transducers and analog antialiasing filters the considered frequency range is limited from 5 to $100 \mathrm{~Hz}$.

2.4 Description of Preliminary Experiments. Using the experimental setup described in Section 2.2, experiments were carried out on a knee joint specimen ( 36 year old male, right knee overall length $40 \mathrm{~cm}$ ) which had been freshly frozen. The experiments were done over a period of two days. During the experiments, the joint was continuously moistened with water to minimize changes in the material properties of the joint elements due to desiccation. The static equilibrium position of the joint was controlled by means of the static preload in the three bracing wires.

The direction of the static loads applied to the joint can be expected to be constant (due to the length of the bracing wires) and is almost parallel to the $Z_{f}$-axis. Although different combinations of static preloads were used, it was possible to keep the flexion angle of the joint at about $20 \mathrm{deg}$, where the flexion angle is defined as the angle between the $Z_{t}$-axis and its projection on the $Y_{f}-Z_{f}$ plane. When changing the static preload, joint movements from a chosen initial equilibrium position were kept as small as possible.

The level of the dynamic input force acting on the tibia, the amount of static preload, and the direction of the dynamic loads applied to the tibia were varied.

Zero-mean, bandwidth-limited white noise containing frequencies between 0 and $100 \mathrm{~Hz}$ was chosen for the dynamic input force. This dynamic force was applied in directions coinciding with the $X_{t}, Y_{t}$, and $Z_{t}$-axis, respectively.

\section{Results}

Figure 7 shows the effect of variation of the static preload upon the transfer function between displacements in $Y_{t}$ direction and the dynamic load $F(t)$ applied in this direction. As for all other experiments, the relevant frequency range was found to be from 5 to $55 \mathrm{~Hz}$. The dynamic behavior was observed to markedly dependent on the level of the static preload: increase of the static preload yields an increase of the 


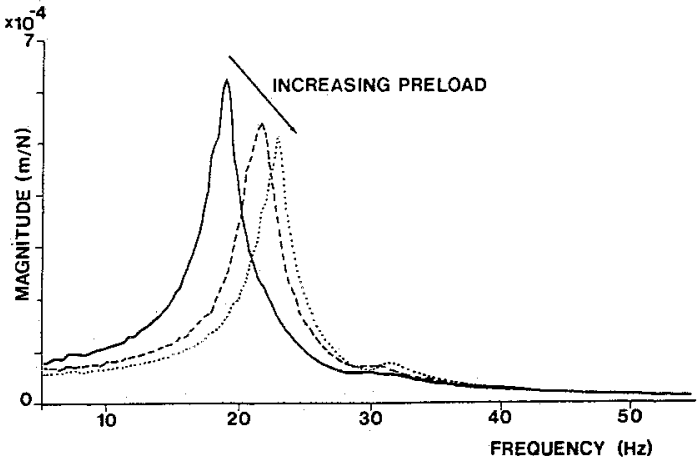

Fig. 7(a) Effect of static preload magnitude on the magnitude of the transfer function between displacements in $Y_{t}$ direction and dynamic force applied in $Y_{t}$ direction.

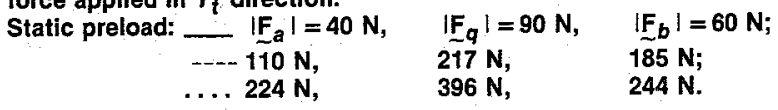

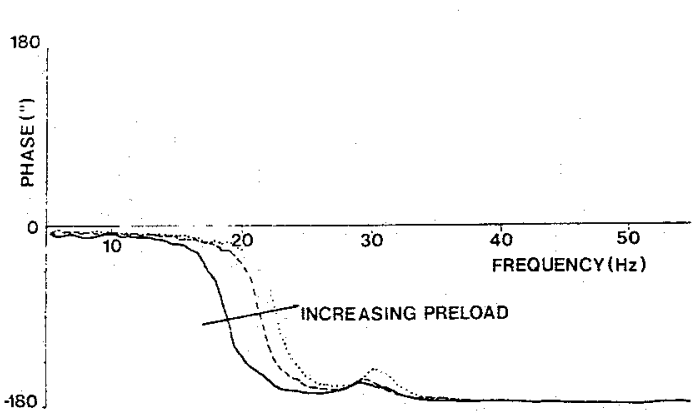

Fig. 7(b) Phase plot corresponding to Fig. 7(a)

dynamic stiffness. This seems to be consistent with the experimental results of Markolf [4]. Similar results were obtained for the transfer functions between displacements and loads applied in $X_{t}$ and $Z_{t}$ direction.

This dependence on the static preload was also found for the reaction forces and torques at the clamped side of the femur (Fig. 8). Since the joint was seen to show clearly nonlinear dynamic properties, it had to be shown that the level of the dynamic input force was small enough to allow for the application of transfer function analysis for the description of the behavior of the locally linearized system. Hence, the dynamic input force was varied at three levels characterized by their mean square value (MSV). For the three levels considered, no significant changes in the transfer functions were found. This is illustrated in Fig. 9 for excitation in $Z_{t}$-direction where the mean square value was subsequently set at $1.8,20.1$, and $87.7 \mathrm{~N}^{2}$. Furthermore, in all experiments the values of the coherence function for the transfer functions were between 0.95 and 1 , leading to the conclusion that under constant static preload, application of transfer function analysis is allowed.

Another concern was the reproducibility of the results. Therefore, some of the experiments of the first day were repeated on the second day after a complete removal of the joint from the experimental setup for storage overnight. Figure 10 shows the result for one such repeated measurement. Only small changes in the transfer functions were found which might be due to decay of the specimen or to a slightly different positioning of the joint.

\section{Concluding Remarks}

An experimental setup has been developed to study the dynamic behavior of the human knee joint in vitro. The first experimental results for one human cadaveric knee tend to in-

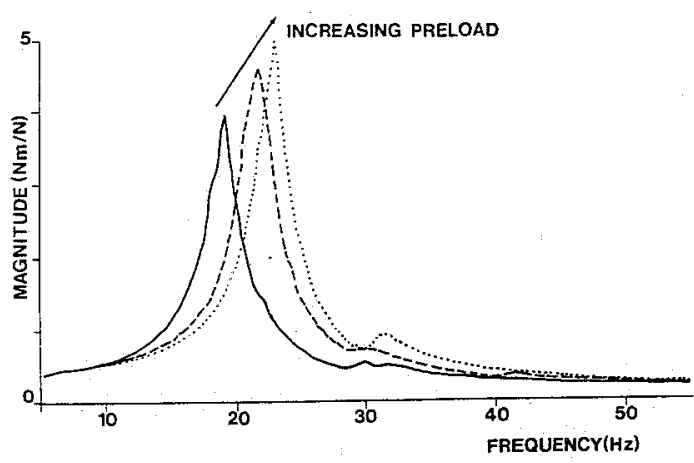

Fig. 8 Effect of static preload magnitude on the magnitude of the transfer function between the reaction torque $T_{X}$ and the dynamic force applied in $Y_{t}$ direction.

\begin{tabular}{|c|c|c|}
\hline Static preload: $\begin{aligned} & \ldots \underset{a}{\mid F_{a}} \mid=40 \mathrm{~N}, \\
& \ldots-110 \mathrm{~N}, \\
& \ldots 224 \mathrm{~N},\end{aligned}$ & $\begin{array}{l}\left|F_{q}\right|=90 \mathrm{~N} \\
217 \mathrm{~N} \\
396 \mathrm{~N}\end{array}$ & $\begin{array}{l}\left|F_{b}\right|=60 \mathrm{~N} \\
185 \mathrm{~N} \\
244 \mathrm{~N} .\end{array}$ \\
\hline
\end{tabular}

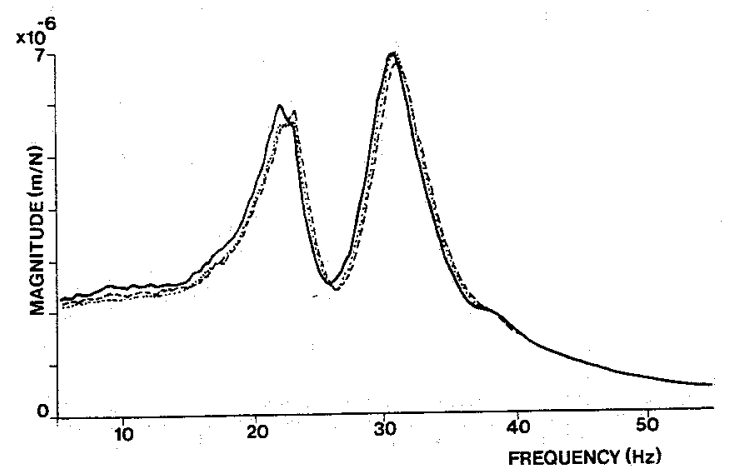

Fig. 9 Effect of the level of the dynamic force applied in $Z_{t}$ direction on the magnitude of the transfer function between displacements in $Z_{t}$ direction and the dynamic force.

Static preload: $\left|F_{a}\right|=125 \mathrm{~N},\left|\underset{\sim q}{\mid F_{q}}\right|=220 \mathrm{~N},\left|\underset{\sim b}{\mid F_{b}}\right|=196 \mathrm{~N}$.

Dynamic force: $\mathrm{MSV} \underset{-1.81 \mathrm{~N}^{2}}{-20.1 \mathrm{~N}^{2}}$

$$
\ldots-87.7 \mathrm{~N}^{2}
$$

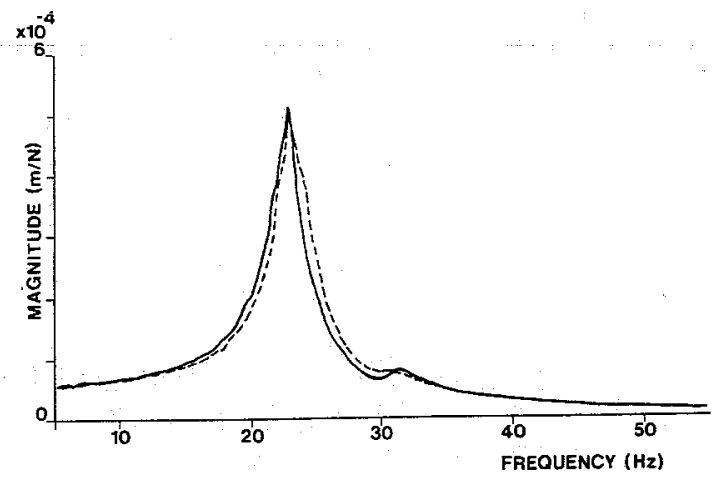

Fig. 10 Effect of mounting/dismounting and storage (16 hr) of the specimen on the transfer function between displacements in $Y_{t}$ direction and the dynamic force applied in $Y_{t}$ direction.

Static preload: $\left|F_{a}\right|=253 \mathbf{N},\left|F_{q}\right|=429 \mathbf{N}|,| F_{b} \mid=258 \mathrm{~N}$.

$$
\text { - day } 1
$$

dicate that force transmission through the knee joint is influenced in a nonlinear way by the level of the static preload.

However, it must be emphasized that further experiments are necessary to establish whether these findings are characteristic for individual joint specimens. These experiments must also be carried out to: 
1) determine how the results are influenced by the level of the total static preload and the load carried by the individual bracing wires;

2) analyze in which sense the dynamic behavior observed depends on the presence of the bracing wires since their finite stiffness might not be negligibly small compared to some of the intrinsic stiffness properties of the joint, in three dimensions;

3) assure that the mean square value of the dynamic load exerted on the tibia permits the assumption that the joint behaves as a linear system under these loads for arbitrary loading directions;

4) investigate how the results are influenced by changes in the static equilibrium position of the joint since these changes may have considerable effect upon the dynamic behavior.

Finally, the influence of the joint elements upon the dynamic force transmission must be investigated. The results of these analyses will then be used to develop a mathematical model which is capable of describing these findings and which allows for a clear interpretation of the function of the different joint elements. These aims are of prime interest in continued research.

\section{Acknowledgments}

We wish to thank Prof. Dr. Ir. J. D. Janssen and Prof. Dr. Ir. D. H. van Campen for their valuable contributions during the preparation of the manuscript.

These investigations are supported by the Netherlands Foundation of Technical Research (S.T.W.), future Technical Science Branch/Division of the Netherlands Organization for the Advancement of Pure Research (Z.W.O.) (Grant: STWEWT25.0259).

\section{References}

1 Wosk, J., and Voloshin, A., "Wave Attenuation in Skeletons of Young Healthy Persons," Journal of Biomechanics, Vol. 14, No. 4, 1981, pp. 261-267. 2 Antonsson, E., and Mann, R., "The Frequency Content of Gait," Journal of Biomechanics, Vol. 18, No. 1, 1985, pp. 39-47.

3 Voloshin, A., and Wosk, J., "Shock Absorption of Meniscectomized and Painful Knees: A Comparative in Vivo Study." Journal of Biomedical Engineering, Vol. 5, 1983, pp. 157-161.

4 Markolf, K., Borgar, W., Shoemaker, S., and Amstutz, H., "The Role of Joint Load in Knee Stability," Journal of Bone and Joint Surgery, Vol. 63-A, No. 4, 1981, pp. 570-585.

5 Wismans, J., Veldpaus, F., Janssen, J., Huson, A., and Struben, P., "A Three-Dimensional Mathematical Model of the Knee Joint;" Journal of Biomechanics, Vol. 13, 1980, pp. 677-685.

6 Sauren, A., Huson, A., and Schouten, R., "An Axisymmetric Finite Element Analylsis of the Mechanical Function of the Meniscus," International Journal of Sports and Medicine, Vol. 5, Suppl. 1984, pp. 93-95.

7 Markolf, K., Mensch, J., and Amstutz, H., "Stiffness and Laxity of the Knee - The Contributions of the Supporting Structures,'” Journal of Bone and Joint Surgery, Vol. 58-A, No. 5, 1976, pp. 583-593.

8 Blankevoort, L., Huiskes, R., and de Lange, A., "The Reproducibility of Passive Human Knee-Joint Motion Characteristics," In Biomechanics: Current Interdisciplinary Research, Eds.: Perren S. M., Schneider E., M. Nijhoff Publ., 1985 , pp. 309-314:

9 Woo, S. L.-Y., Gomez, M. A., and Akeson, W. H., "The Time and History-Dependent Viscoelastic Properties of the Canine Medial Collateral Ligament," Journal of Biomechanical Engineering, Vol. 103, 1981, pp. 293-298.

10 Mow, V. C., Holmes, M. H., Lai, W. M., "Fluid Transport and Mechanical Properties of Articular Cartilage: A Review," Journal of Biomechanics, Vol. 17, No, 5, 1984, pp. 377-394.

11 Crowninshield, R., Pope, M., Johnson, R., and Miller, R., "The Impedance of the Human Knee," Journal of Biomechanics, Vol. 9, 1976, pp. $529-535$.

12 Moeinzadeh, M., Engin, A., and Akkas, N., "Two Dimensional Dynamic Modelling of Human Knee Joint," Journal of Biomechanics, Vol. 16, No. 4, 1983 , pp. $253-264$

13 Bendat, J., and Piersol, A., Engineering Applications of Correlation and Spectral Analysis, Wiley-Interscience, 1980.

\title{
CALL FOR PAPERS ASME BIOENGINEERING DIVISION
}

\author{
ASME Winter Annual Meeting \\ Hyatt Regency, Chicago, Illinois \\ November 28-December 2, 1988
}

\section{AREAS OF INTEREST}

1. Biofluid Mechanics

2. Biosolid Mechanics

3. Biomedical Heat \& Mass Transfer

4. Rehabilitation Engineering

5. Medical Devices \& Artificial Organs

6. Computational Methods (Special Symposium)

7. Tissue Mechanics

8. Bone Mechanics \& Implants

9. Bioinstrumentation

\section{SUBMISSION AND PUBLICATION}

Extended abstracts should be submitted on author-prepared mats. Accepted abstracts will be published in the 1988 Advances in Bioengineering. For mats and additional information, contact:

\author{
Dr. Gerald Miller \\ Bioengineering Program \\ Texas A\&M University \\ 326 Teague Building \\ College Station, Texas 77843-3120
}

\section{DEADLINE DATES}

Submission of Abstracts

Notification of Authors 